\title{
Determinação do poder calorífico do carvão vegetal comercializado no centro da cidade de Patos-PB
}

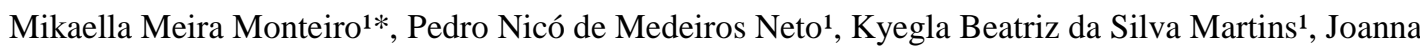 \\ Letícia Diniz Melo ${ }^{1}$, Natielly Cristine Gomes de Medeiros ${ }^{1}$, Carlos Magno Pereira de Souza Junior ${ }^{1}$
}

\begin{abstract}
RESUMO: O carvão vegetal é um combustível comumente utilizado para uso doméstico, para cozimento de alimentos e fonte de aquecimento em certas partes do mundo, especialmente África e o Sudeste Asiático. Este trabalho teve por objetivo estudar a determinação do poder calorífico do carvão vegetal comercializado na região central do município de Patos, estado da Paraíba. Foi adotado um processo de amostragem aleatório com os estabelecimentos comerciais divididos nas seguintes categorias: supermercados (S), casa de carnes e/ou açougues (A), e conveniências (C) que comercializavam este produto vegetal. De cada embalagem foi obtido uma amostra de um quilograma de carvão vegetal para avaliar o seu poder calorífico superior (PCS), inferior (PCI) e útil (PCU). A maior média para o PCS é encontrada no frigorífico marca R1 $\left(8160,45 \mathrm{kcal} \mathrm{kg}^{-1}\right)$, nota-se que a menor média do PCS $\left(7092,09 \mathrm{kcal} \mathrm{kg}^{-1}\right)$ foi encontrada nessa mesma marca, no supermercado e consequentemente a mesma tendência para o PCI e o PCL. Isto pode estar relacionado com a idade, condições edafoclimáticas e condições do processo de carbonização da matéria prima de origem. Os valores de poder calorífico são muito variados entre as marcas e dentro do próprio estabelecimento comercial, indicando uma grande heterogeneidade do material avaliado.
\end{abstract}

Palavras-chave: energia, fonte renovável, heterogeneidade.

\section{Determination of the calorific value of charcoal marketed in the city center of Patos-PB}

Charcoal is a commonly used fuel for domestic use, for cooking food and a source of heating in certain parts of the world, especially Africa and Southeast Asia. This study aimed was to study the calorific value of charcoal marketed in the central region of the municipality of Patos, state of Paraiba. A random sampling process was adopted with commercial establishments divided into the following categories: supermarkets $(S)$, meat house and / or butchers $(H / B)$, and conveniences $(C)$ that commercialized this vegetable product. From each package a sample of one kilogram of charcoal was obtained to evaluate its superior calorific value (SCV), inferior (SCI) and useful (SCU). The highest mean for SCV is found in the refrigerator R1 (8160.45 kcal kg-1), it is noted that the lowest mean SCV (7092.09 kcal kg-1) was found in the same brand, in the supermarket and consequently the same trend for SCI and SCU. This may be related to the age, soil and climatic conditions and conditions of the carbonization process of the raw material of origin. The values of calorific value are very varied between the brands and within the commercial establishment itself, indicating a great heterogeneity of the evaluated material.

Keywords: energy, renewable source, heterogeneity.

\section{INTRODUÇÃO}

O carvão vegetal é um combustível comumente utilizado para uso doméstico, para cozimento de alimentos e fonte de aquecimento em certas partes do mundo, especialmente África e o Sudeste Asiático (PENNISE et al., 2001). O Brasil destacase por ser o maior produtor e consumidor de carvão vegetal em escala mundial com 1,1 de hectares de florestas plantadas no território brasileiro, com produção de 4,5 milhões de toneladas produzidas (Indústria Brasileira de Árvores - IBÁ, 2017).

De acordo com Instituto Brasileiro de Geografia e Estatística - IBGE (2016), a produção de carvão vegetal na região do Nordeste brasileiro com relação a extração vegetal para produção de carvão vegetal, foi de 354.810 toneladas e, dentre os estados nordestinos, a Paraíba produziu 799 toneladas, gerando um valor de $\mathrm{R} \$ 767.000$, ocupando a quinta posição entre os estados produtores de carvão vegetal nesta região geográfica do país. Quando observado, sua produção no município de Patos $\mathrm{PB}$, este produziu 81 toneladas, totalizando um valor de $\mathrm{R} \$ 82.000$ na economia do município.

Diante desta demanda, existe a necessidade de avaliar a qualidade deste carvão vegetal comercializado para o consumo doméstico, sendo características desejáveis uma elevada massa específica, alto teor de carbono fixo, baixo teor de umidade, baixo teor de materiais voláteis e cinzas e principalmente um alto poder calorífico. Este último destaca-se como um dos principais parâmetros de qualidade, em virtude, de representar a quantidade de energia liberada durante a combustão do material, sendo essencial para descriminar a capacidade energética de determinada espécie florestal (CARNEIRO et al., 2014).

Este parâmetro, pode ser obtido de três maneiras distintas, ou seja, o poder calorífico superior, inferior e líquido. $\mathrm{O}$ primeiro está relacionado a

\footnotetext{
Recebido em 05/07/2019, Aceito para publicação em 15/10/2019

${ }^{1}$ Universidade Federal de Campina Grande

*e-mail: mikaellaflorestal@gmail.com
} 
quantidade de calorias liberada durante a queima do material e a água formada durante o processo é condensada, determinado pelo método calorimétrico. Já o inferior é calculado quando desconta-se o calor latente do vapor d'água durante a queima. Em relação ao liquido, este representa a quantidade de energia térmica a ser perdida em virtude da queima do material (BRAND, 2010).

Diante disso, este trabalho teve como objetivo a determinação do poder calorífico do carvão vegetal comercializado na região central do município de Patos, estado da Paraíba.

\section{MATERIAL E MÉTODOS Amostragem do carvão vegetal}

De cada embalagem foi obtido uma amostra de um kilograma de carvão vegetal para avaliar o seu poder calorífico superior, inferior e útil. Para realização das análises o carvão vegetal foi triturado e classificado em peneiras granulométricas, sendo utilizada a fração que passar pela peneira de 40 mesh e ficar retida na malha de 60 mesh.

O poder calorífico superior foi determinado pelo emprego de um calorímetro adiabático de acordo com a Norma Brasileira Regulamentadora -NBR 8633 da Associação Brasileira de Normas Técnicas ABNT (1983) e o poder calorífico inferior (base seca) foi estimado mediante a Equação 1, uma vez que não foi possível a obtenção do valor do teor de hidrogênio do material.

$$
\begin{gathered}
\text { PCI }=\text { PCS }-324 \\
\text { (Equação 1) }
\end{gathered}
$$

em que: PCI: poder calorífico inferior $\left(\mathrm{kcal} \mathrm{kg}^{-1}\right)$; PCS: poder calorífico superior $\left(\mathrm{kcal} \mathrm{kg}^{-1}\right)$.Para a determinação do poder calorífico líquido, este foi estimado com base na Equação 2:

$$
P C L=\left(\left[\left(P C I-\left(\begin{array}{c}
6 * U b s) \\
100
\end{array}\right] /(100+U b s)\right) *\right.\right.
$$

(Equação 2)

em que: PCL: poder calorífico líquido $\left(\mathrm{kcal}^{-1}\right)$; PCI: poder calorífico inferior $\left(\mathrm{kcal} \mathrm{kg}^{-1}\right)$; Ubs: umidade média na base seca (\%).

Os dados foram avaliados por meio da estatística descritiva, utilizando a média aritmética das repetições realizadas em cada amostra.

\section{RESULTADOS E DISCUSSÃO}

Com base na Tabela 1, observa-se que a maior média para o PCS é 8160,45 kcal kg-1 encontrada no frigorífico (marca R1), nota-se que a menor média do PCS $\left(7092,09 \mathrm{kcal} \mathrm{kg}^{-1}\right)$ é encontrada nessa mesma marca e consequentemente a mesma tendência para o PCI e o PCL. Isto pode estar relacionado com a idade, condições edafoclimáticas e condições do processo de carbonização da matéria prima de origem.

Todas as amostras coletadas tinham como fonte de matéria prima para a produção do carvão vegetal, destacada na embalagem comercializada a madeira de algaroba (Prosopis juliflora).

TABELA 1. Valores médios do poder calorifico superior,

\begin{tabular}{|c|c|c|c|c|c|}
\hline $\begin{array}{l}\text { Local de } \\
\text { venda }\end{array}$ & $\begin{array}{c}\mathrm{M} \\
\text { arca }\end{array}$ & $\begin{array}{l}\text { Am } \\
\text { ostra }\end{array}$ & $\begin{array}{c}\mathrm{PC} \\
\mathrm{S} \\
\begin{array}{c}\mathrm{kcal} \mathrm{kg}_{1} \mathrm{~kg}^{-} \\
{ }^{-}\end{array}\end{array}$ & $\begin{array}{r}\text { PCI } \\
\begin{array}{c}( \\
\mathrm{kcal} \mathrm{kg}^{-} \\
\left.{ }^{1}\right)\end{array} \\
\end{array}$ & $\begin{array}{c}\mathrm{PC}^{\mathrm{PC}} \\
( \\
\mathrm{kcal} \mathrm{kg} \\
\left.{ }^{1}\right)\end{array}$ \\
\hline $\begin{array}{l}\text { Supermer } \\
\text { cado }\end{array}$ & ${ }_{1}^{\mathrm{R}}$ & 2 & $\begin{array}{l}752 \\
1,99\end{array}$ & $\begin{array}{l}719 \\
7,99\end{array}$ & $\begin{array}{r}\quad 698 \\
4,12\end{array}$ \\
\hline $\begin{array}{l}\text { Frigorífic } \\
\quad \mathrm{o}\end{array}$ & ${ }_{1}^{\mathrm{R}}$ & 2 & $\begin{array}{l}\quad 803 \\
3,02\end{array}$ & $\begin{array}{l}770 \\
9,02\end{array}$ & $\begin{array}{l}762 \\
6,75\end{array}$ \\
\hline Minibox & ${ }_{1}^{\mathrm{R}}$ & 2 & $\begin{array}{c}739 \\
5,09\end{array}$ & $\begin{array}{c}707 \\
1,09\end{array}$ & $\begin{array}{l}684 \\
5,5\end{array}$ \\
\hline $\begin{array}{l}\text { Frigorífic } \\
\text { o } \\
\text { Conveniê } \\
\text { ncia }\end{array}$ & $2^{2} \mathrm{R}$ & 2 & $\begin{array}{c}798 \\
6,02 \\
734 \\
2,61\end{array}$ & $\begin{array}{l}766 \\
2,01\end{array}$ & $\begin{array}{c}746 \\
0,5 \\
694 \\
3,17\end{array}$ \\
\hline
\end{tabular}
inferior e liquido do carvão vegetal comercializado no município de Patos-PB.

Fontes: os autores

Fonsêca (2011) ao avaliar o carvão vegetal da madeira de Prosopis juliflora, constatou um poder

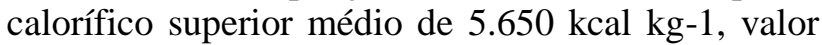
inferior aos encontrados no presente trabalho, provavelmente resultante da origem distintas dos materiais avaliados.

Costa et al. (2017), ao avaliarem a qualidade do carvão vegetal, proveniente de madeira de espécies nativas, para a cocção de alimentos comercializados em Cuiabá-MT, obtive resultados de PCS inferiores ao encontrados neste trabalho, com médias menores que $8000 \mathrm{kcal} \mathrm{kg}^{-1}$.

Rosa et al. (2012), ao analisar a qualidade do carvão vegetal para o uso doméstico, constataram valores entre 7400 e $7800 \mathrm{kcal} \mathrm{kg}^{-1}$ para poder calorífico superior. Outros autores como Brandt et al. (2015) e França (2015) encontraram 7086 e 7968 $\mathrm{kcal} \mathrm{kg}^{-1}$, respectivamente, estes valores são semelhantes aos encontrados em algumas amostras das marcas observadas, assim como os valores obtidos por Oliveira et al. (2015) ao examinar a qualidade do carvão vegetal provenientes de espécies exóticas e de reflorestamento comercializados no Paraná, onde a maior média obtida foi 7443,9 kcal.kg-1.

Para o poder calorífico inferior, o maior valor constatado neste trabalho foi $7836,45 \mathrm{kcal} \mathrm{kg}^{-1}$ e o menor valor encontrado foi $6768,09 \mathrm{kcal} \mathrm{kg-}^{-1}$. Notase que esses valores foram encontrados na mesma marca (R1). Estes valores se mostram superiores quando comparados aos trabalhos de Souza et al. 
(2012) e Silva et al. (2015), que encontraram médias 4602 e 4379, $1 \mathrm{kcal} \mathrm{kg}^{-1}$, respectivamente.

Costa et al. (2017) alega que o poder calorífico líquido retrata a quantidade efetiva de energia cedida pela massa do combustível, visto que reduz a energia necessária para a evaporação da água que está contida no material. $\mathrm{O}$ maior valor obtido neste trabalho para o PCL foi 7626,75 $\mathrm{kcal} \mathrm{kg}^{-1}$. Dias Junior et al. (2018), ao estudar o carvão vegetal oriundas de madeira de eucalipto e outras espécies provindas das regiões de Minas Gerais e Paraná, para cocção de alimentos em Piracicaba-SP, constatou valores superiores a $8000 \mathrm{kcal} \mathrm{kg}^{-1}$ para PCL, superando os resultados deste trabalho. Já a maioria das médias encontradas por Costa et al. (2017) são inferiores quando comparadas aos valores observados nesse trabalho.

\section{CONCLUSÃO}

Para o poder calorífico do carvão vegetal foi observada uma elevada variação entre as marcas e dentro do próprio estabelecimento comercial, indicando uma grande heterogeneidade do material avaliado.

As maiores médias encontradas para o poder calorífico superior foi de 8160,45 e 8033,02 kcal kg1, estes valores foram encontrados para a marca R1, comercializada em um frigorífico, com menor valor para a mesma marca $\left(7092,09 \mathrm{kcal} \mathrm{kg}^{-1}\right)$, porém localizada em um supermercado.

\section{REFERÊNCIAS}

ANATER, M. J. N. Qualidade do carvão vegetal para uso doméstico comercializado em Curitiba. 2017. $74 \mathrm{f}$. (Mestrado em Bioenergia) - Universidade Federal do Paraná, Paraná.

ASSOCIAÇÃO BRASILEIRA DE NORMAS TÉCNICAS - ABNT. NBR 8633: carvão vegetal determinação do poder calorífico. Rio de Janeiro: 1983. $13 p$.

BRAND, M. A. Energia de biomassa florestal. Editora Interciência, 2010. 114 p.

CARNEIRO, A. C. O.; CASTRO, A. F. N. M.; CASTRO R. V. O.; SANTOS, R. C.; FERREIRA, L. P.; DAMÁSIO R. A. P.; VITAL, B. R. Potencial energético da madeira de Eucalyptus sp. em função da idade e de diferentes materiais genéticos. Revista Árvore, v. 38, n.2, p. 375381, 2014.

COSTA, A. C. S.; OLIVEIRA, A. C., FREITAS, A. J., LEAL, C. S., PEREIRA, B. L. C. Qualidade do carvão vegetal para cocção de alimentos comercializado em Cuiabá - MT. Nativa, Sinop, v.5, n.6, p.456-461, 2017.
DIAS JUNIOR, A. F. Carvão vegetal para cocção de alimentos: aspectos mercadológicos e de qualidade para o consumo. 2018. 105 f. Tese (Doutorado em Engenharia Florestal) - Universidade de São Paulo, São Paulo.

FONSÊCA, C. M. B. Estudo comparativo do potencial energético do juazeiro (Ziziphus joazeiro Martius) e da algarobeira (Prosopis juliflora (SW.) DC.) na produção de carvão no semiárido paraibano. 2011. 60 f. Dissertação (Mestrado em Ciências Florestais) Universidade Federal de Campina Grande, Paraíba.

FRANÇA, R. F. Estrutura anatômica da madeira e do carvão de espécies da caatinga. 2015. 100f. Dissertação (Mestrado) Engenharia Florestal - Universidade Federal do Paraná.

INDÚSTRIA BRASILEIRA DE ÁRVORES - IBÁ. 2017. Anuário estatístico da IBÁ, ano base 2016. 100p.

INSTITUTO BRASILEIRO DE GEOGRAFIA E ESTATÍSTICA - IBGE. Produção da Extração Vegetal e da Silvicultura. Ano 2016. Disponível em: <http://https://ww2.ibge.gov.br/home/estatistica/economia /pevs/2016/default_xls.shtm>. Acesso em: 02 maio de 2018.

OLIVEIRA, A. F.; BAVARESCO, A., PESSUTI, A. A. C., MIYASHIRO, C. S., FRANK, J. Análise da qualidade do carvão para consumo doméstico de quatro municípios do Estado do Paraná. Revista Brasileira de Energias Renováveis, Curitiba, v.4, p. 102- 111, 2015.

PENNISE, D. M.; SMITH, K. R.; KITHINJI, J. P.; REZENDE, M. E.; TULIOJ ARDIM RAAD, T. J.; ZHANG, J.; FAN, C. Emissions of greenhouse gases and other airborne pollutants from charcoal making in Kenya and Brazil. Journal of Geophysical Research, v.106, n.20, p. 143-155, 2001.

ROSA, R. A.; CHAVES ARANTES, M. D., PAES, J. B., ANDRADE, W. S. D. P., MOULIN, J. C. Qualidade do carvão vegetal para o consumo doméstico. Journal of Biotechnology and Biodiversity, v.3, n. 2, p. 1165-1173, 2012.

SILVA, D. A.; MÜlLER, B. V., KUIASKI, E. C., ELOY, E.; BEHLING, A., COLAÇO, C. M. Propriedades da madeira do Eucalyptus benthamii para produção de energia. Pesquisa Floresta Brasileira, Colombo, v. 35, n. 84, p. 481-485, 2015.

SOUZA, M. M.; SILVA, D. A., ROCHADELLI, R., SANTOS, R. C. Estimativa de poder calorífico e caracterização para uso energético de resíduos da colheita e do processamento de Pinus Taeda. FLORESTA, Curitiba, PR, v. 42, n. 2, p. 325 - 334, 2012. 